\title{
The Causes and Consequences of Rural-urban Migration: The Case of Wolaita Sodo Town Merhal Sub-City.
}

\author{
Mesele Woldemichael Delango \\ Department of Civics and Ethical Studies, College of Social Sciences and Humanities, Wolaita Soddo \\ University, Wolaita Soddo, Southern Ethiopia \\ meselew.michael@yahoo.com
}

\begin{abstract}
In developing countries like Ethiopia rural-urban migration is an image that distresses development in both urban and rural areas. Hence, this study was aimed to identify and investigate the major causes and consequences of rural-urban migration in Wolaita Sodo town Merhal Sub-city. With a confidence level of 90\%, the sample sizes of 95 target respondents were determined by using Cochran s formula for sample size determination, but due to time and budget constraints the researcher reduced the sample size in to 50 from two $k$ respective kebeles. Both qualitative and quantitative data was collected from primary and secondary sources. The qualitative data was analyzed by using table, percentage, mean, frequency and graph and qualitative data obtained from Focus FGDs and key informants were analyzed through narration and qualitative descriptions. Hence problems such as financial (24\%), unemployment (30\%), inability to obtain social services (14\%) and, do not get job as expected (30\%) are now evident in the study areas. Taking into account the population growth of the town, constructing additional house and social service centers, such as schools, health institutions, recreational centers are important in providing needed services and better quality of life. Therefore, it needs GOs and NGOs considerable attention and other policy-makers to reflect on the most suitable ways to the existing problem.
\end{abstract}

Keywords: Migration; Socio-cultural factor; rural-urban migration; Cause and effects of migration

\section{Introduction}

Migration is considered as the movement of people from one geographic region to another, which maybe on temporary or permanent basis. The reasons for it vary from one person to another depending on the situation that brought about the decision (Adewale, 2005). Generally, rural-urban migration dominates the domain of research as its role in changing the lives of migrants and families at the place of origin and destination (Hossain, 2001).

Thus, rapid geographic shift of people from the rural to urban region in different countries has been the result of the combination of both rural push and urban pull factors (Farooq and Cheema, 2005; Hossain, 2001; Ullah, 2004). This rural-urban migration in developing countries is accompanied by positive and negative consequences for the area of origin and destination. For the rural people, in the short run it may help to alleviate the poverty by creating new income and employment opportunity and it has helped in facilitating rural-urban economic and social integration and motivating the expansion of the urban sector. Later, this alarming migration process has led to congestion, unemployment, pollution and poverty in urban areas, gender and age imbalances and decrease in productivity in rural areas (Aliyev, 2008).

Migration has been seen as a response of individuals to better their economic and noneconomic of opportunities as well as an expectation of increased economic welfare in the urban areas. factors that push individuals from rural areas into cities include the expectation that the pressure of population in rural areas has nearly exhausted all margins of cultivation, 
thus pushing hopeless people towards a new life in the cities with a mere expectation of subsistence living (Mazumdar,1987). On the other hand, the pull hypothesis emphasizes the attractiveness of the urban life and the rural-urban wage gap. In particular, Todaro (200) developed probabilistic models, where in they describe migrants are attracted to the cities with the expectation of a higher wage than they receive in agriculture, and are willing to accept the probability of urban unemployment, or lower wages and under employment in the urban informal (traditional) sector. Ethiopia is one of the countries in Africa with a relatively high level of internal migration and population redistribution. This was associated with the country's economic transition from a socialist to a market oriented economy; critical political changes since the 1970s through 1990s; civil war; and famine (Berhanu and White, 2000; Kiros and White, 2004).

Researchers have shown how the character; direction, and the volume of migration in Ethiopia during the last two to three decades have been shaped by political instability decline in the agricultural sector and government resettlement policies of the 1980s. The latter had as an official objective to prevent further famine and to attain food security (Ezra, 2001). Under these circumstances, migration in Ethiopia was not only an individual and/or family response to adverse Socio economic, physical and political environment, but also as a result of official government policy.

In Ethiopia, rural-urban migration is quite common especially in areas where drought is frequent. Regarding to the causative factors of rural-Urban migration in Ethiopia, scholars identified that the combined affects of push and pull factors are responsible for the wave of migration to urban areas of Ethiopia. However, the history show that, more than Urban pull factors rural push factors have been strong forces for the movement of people from rural to urban areas of Ethiopia (Markos, 2001). In line with this statement, Solomon and Mansberger (2003) state that, after all in Ethiopia, population is on the rise, land degradation has become common and the rural areas are being rocked by frequent drought and famine. In view of these, one would expect arrival of the rural people to the cities to happen. Then the wave of migration to urban areas of Ethiopia is consistently higher than the capacity of urban areas to accommodate the new demands posed by the migrants.

Thus, there is wide spread of unemployment, shortage of housing, increasing cost of living, and lack of access to social service is existed. Due to the varied factors of migration (push and pull), currently, there is excessive movement of people to Southwest Ethiopia. Thus, at the present time there is a continuous flow of people from rural area bombe town who have throw away their role in the farms, and have engaged themselves in the urban informal economic sector. Although, these problems have larger dimension, pervasive and continuing unabated, research is scarce to monitor trend of movement of the people on a sustainable basis. Thus, the motivation of the researcher is to fill this knowledge gap and to study the main factors behind the movement of the rural people. Hence, this research was focused on identifying major cause that enhances continuous flow of people from rural area to wolaita Sodo Town.

The study has intended to specify both general and specific objectives. The general objectives of the study are to assess the causes and consequences of rural-urban migration in 
Wolaita Sodo Town Merhal Sub-city. Regarding the area of investigation, this study is delimited to the study on assessment of the causes and consequences of rural-urban migration in Wolaita Sodo Town, Merhal Sub-city. With regard to its significance, the findings of this study are expected to make modest but important contributions to policy and planning issues, because it may be helpful in tackling the problems that force people to leave their rural origin and narrowing the development gap between urban and rural areas through the introduction of sound rural development strategies and effective Urban management. It also contribute to fill the gap concerning migrant informal sector participants and the giving information related to rural urban migrant which has a direct relation to planning and implementation agencies as well as institutions because rural-urban migration has a direct and indirect effect on the geographical as well as social, cultural and economic aspects.

Hence, this study is important all other field of studies, because rural-urban migration in relation to informal sector is taken as a socio-economic and cultural phenomenon which is concerned with population issues. Furthermore, this study helped to support and inspire other researchers who want to deal with the cause and consequence of rural-urban migration; to conduct further research on the issue, policy makers can use this study to strengthen policy issues related to rural-urban migration, and it helps to widen the knowledge base in relation to rural-urban migration.

This research is structured as follows: section one presents the introduction, statement of the problem, objectives of the study, limitation of the study, significance of the study. The second section presents the research methodology, the third section presents about results and discussion and the last section presents conclusion and recommendation of the research.

Thus, there is wide spread of unemployment, shortage of housing, increasing cost of living, and lack of access to social service is existed. Due to the varied factors of migration (push and pull), currently, there is excessive movement of people to Southwest Ethiopia. Thus, at the present time there is a continuous flow of people from rural area bombe town who have throw away their role in the farms, and have engaged themselves in the urban informal economic sector. Although, these problems have larger dimension, pervasive and continuing unabated, research is scarce to monitor trend of movement of the people on a sustainable basis. Thus, the motivation of the researcher is to fill this knowledge gap and to study the main factors behind the movement of the rural people. Hence, this research was focused on identifying major cause that enhances continuous flow of people from rural area to wolaita Sodo Town.

The study has intended to specify both general and specific objectives. The general objectives of the study are to assess the causes and consequences of rural-urban migration in Wolaita Sodo Town Merhal Sub-city. Regarding the area of investigation, this study is delimited to the study on assessment of the causes and consequences of rural-urban migration in Wolaita Sodo Town, Merhal Sub-city. With regard to its significance, the findings of this study are expected to make modest but important contributions to policy and planning issues, because it may be helpful in tackling the problems that force people to leave their rural origin and narrowing the development gap between urban and rural areas through the introduction of sound rural development strategies and effective Urban management. It also contribute to fill the gap concerning migrant informal sector participants and the giving information related 
to rural urban migrant which has a direct relation to planning and implementation agencies as well as institutions because rural-urban migration has a direct and indirect effect on the geographical as well as social, cultural and economic aspects.

Hence, this study is important all other field of studies, because rural-urban migration in relation to informal sector is taken as a socio-economic and cultural phenomenon which is concerned with population issues. Furthermore, this study helped to support and inspire other researchers who want to deal with the cause and consequence of rural-urban migration; to conduct further research on the issue, policy makers can use this study to strengthen policy issues related to rural-urban migration, and it helps to widen the knowledge base in relation to rural-urban migration.

This research is structured as follows: section one presents the introduction, statement of the problem, objectives of the study, limitation of the study, significance of the study. The second section presents the research methodology, the third section presents about results and discussion and the last section presents conclusion and recommendation of the research.

\section{Methodology}

In this part the researcher tried to mention the research methodology- including the research design, data collection techniques and tools and analysis methods which have been used to carry out this research and they are listed and discussed briefly below. This was cross sectional community based study comprised of both triangulated quantitative and qualitative design. This helps to understand the social world through an examination of the interpretation of that world by its participants and hence, in this study, it is employed to gain a better understanding about the causes and conseqeunces of rural-urban migration.

The data for this study was obtained from Wolaita Sodo Town Merhal sub-city. The study area was purposively selected since it is largest proximal city in Southern Ethiopia, where the large rural urban migration problem is witnessed from drought prone areas. Merhal sub-city is the one of the 3 Sub-cities in Wolaita Sodo town administration. Among 6 kebeles those exist in Merhal sub-city; two kebeles namely Gido and Wadu were purposively selected depending on secondary information sources from central statistical agency in sodo town, where most rural urban migration is evident.

With a confidence level of $90 \%$ the sample size of 95 target respondents were calculated by using population proportion to size (PPS), among them 26 and 24 migrants were selected from 01 and 02 kebele administrations in Merhal sub-city respectively. The random sampling was used as an appropriate technique because it avoids bias of representative and all people in the population have an equal chance of being selected. The other is within the study population at a time of study there may be some households who are not present at that area to give response in addition random sampling is helpful in timely performing the study.

Cochran s formula: $\mathrm{N} / 1+\mathrm{N}^{*}(\mathrm{e})^{2}$

Where $\mathrm{N}=$ number of target population, $\mathrm{e}=$ margin of error at $10 \%, \mathrm{n}=$ sample size 
By using formula: Cochran s Sample size determination formulas $\mathrm{N}=1820 / 1+1820 *(10 \%)^{2}$

$1+\left(\mathrm{N}^{*} \mathrm{e}^{2}\right)=95$. Therefore sample size of the two kebeles is 95 , but due to time and budget constraints the researcher reduced the sample size to 50 from two k respective kebeles.

Table 1. Total migrant and sample size

\begin{tabular}{|l|l|l|}
\hline \multicolumn{1}{|c|}{ Kebele } & \multicolumn{1}{c|}{ Migrant } & \multicolumn{1}{c|}{ Sample } \\
\hline 01 & 940 & 26 \\
\hline 02 & 880 & 24 \\
\hline Total & $\mathbf{1 8 2 0}$ & $\mathbf{5 0}$ \\
\hline
\end{tabular}

Source: Own Survey 2019

Both qualitative and quantitative data was collected from primary and secondary source to identify important factors that affect rural-urban migration. Quantitative primary data was collected by using migrant survey. Qualitative primary data was collected using key informants where elderly and knowledgeable people about the area were asked on various issues relevant to study. On the other hand, secondary data was obtained from published and unpublished sources.

The researcher used informal survey to collect background information that was useful for subsequent survey. Then formal survey was conducted to analyze the cause and effects of rural urban migration on the study area by using questionnaire, interview and focus group discussion. Questionnaires were prepared to obtain quantitative data from the respondents. The interview was also helped to gather necessary information through asking questions and writing down the response of the respondents which build research purpose. It was proposed to those people that were selected as a sample. On the other hand, focus group discussion was used by the researcher to obtain qualitative data. FGD allows for a dialogue among participants and stimulates them to openly express their views on the issues raised. The researcher personal observation and experience of the study was helped him to understand the consequences of rural urban in the study area.

The quantitative data acquired through close-ended questionnaire items was organized and displayed in tables to be analyzed quantitatively through the application of statistical techniques of percentage and frequencies. While the qualitative data obtained and elicited through open-ended questionnaire items were obtained from Focus Group Discussions (FGDs) and key informants were analyzed through narration and qualitative descriptions.

\section{Discussion}

In this section, we are going to provide results that are analyzed and interpreted based on the data gathered from sample respondents, FGD and key informants by the prepared questionnaire on the socio-demographic characteristics of migrants, factors motivating for rural-urban migration and its consequence on the place of destination. 


\subsection{Demographic Background of Respondents}

Under demographic background of the respondents, the researcher presented and discussed variables such as age, religion, marital status, educational level, and head of the household of the sample respondents on the migrants, factors motivating for rural-urban migration and its consequence on the place of destination.

\section{a. Age and sex structure of migrants}

Age is one of the demographic factor make people to migrante and occupied in better way of living standard,this is because the young age groups seems are less satisfied with the rural agricultural system and are more ambitious to test urban life. Internal migration is an activity undertaken primarily by young adults all over the world (Deshingkar and Grimm, 2004). In line with the above discussion, the results of this study shows that, the rate of migration was found significantly higher for the people who belonged to the age group of (15-60) followed by (30-45) about $42 \%$ and 32\%, respectively, (indicating that youths, among others, are more migratory) and the rate was about $16 \%$ among the age group of (4560) years and above 60 age was 10\%( see Table.3). In terms of gender as one of the demographic factor, perhaps the most important form of social differentian that influence migration propensities so migration is also sex selective not only age. In-migrants to Wolaita Sodo are dominated by the male with proportion of $76 \%$ and it is $24 \%$ for female migrants (Table 3).

Table 2 Ages of Migrants and Percentage Distribution

\begin{tabular}{|c|c|c|}
\hline Age category of migrant & Respondents & Percentages \\
\hline $15-30$ & 21 & 42 \\
\hline $31-45$ & 16 & 32 \\
\hline $46-60$ & 8 & 16 \\
\hline$>60$ & 5 & 10 \\
\hline Total & $\mathbf{5 0}$ & $\mathbf{1 0 0}$ \\
\hline
\end{tabular}

Source: Own Survey 2019

The age of migrants clearly shows that majority of them were very young at the time of their first migration. The proportion of migrants remarkably decreased with increasing in age group. The average age of migration was found about 21 years with standard deviation of 3.44 years. Thus, the rural migrants to urban are concentrated among youth. This proves that children and elderly are less interested in rural- urban migration.

\section{b. Education Level of Migrants}

Education is one of the demographic factors that make people to migrate urban cities for the case better education services. Most studies of rural-urban migration found that, relatively better educated shows the highest susceptibility to migrate (Deshigkar and Grimm, 2005; Hossain, 2001). But the findings of CSA (1999) in Ethiopia showed that $70 \%$ of internal migrants were illiterate. In line with these, the results show that $34 \%$ of migrants were illiterate and there are a proportion of migrants who attained primary school $(24 \%)$, of whom $16 \%$ were at primary school level of first cycle (grade 1-4) and 10\% were attended 
second cycle level ( grade 5-8). The rest were $27.5 \%$ of migrants were general secondary cycle (9-10) and one case of each who attained grade 11-12 was $12 . \%$ and more than grade 12 among migrants were $4 \%$. This does suggest that illiterate peoples are the most migratory (Table 3) and it is similar with that of findings of CSA and inversely related with Deshigkar and Grimm, and Hossain.

\section{c. Marital status}

The migration decision of an individual of an individual is also influenced by marital status. Different literatures stated that generally those who have no family obligation are more prone to move (IDRC, 1977; Mendola, 2006). Supporting this idea, the result of this study shows that majority of $(40 \%)$ of the migrants were single, $32 \%$ of the migrants were married, $10 \%$ were divorced, $10 \%$ of migrants are separated and $5 \%$ of migrants were widowed at the time of their migration (Table3). In general from the study the persons who have no family (single) peoples are more chance to leave the place of origin and engaged in better environment.

\section{d. Head of the household}

The study found that, although a few of the households are female headed households as compared to male headed households from the migrants origin of the rural site, male headed households were more likely to be the source of rural-urban migrants than the female counterparts. Rural-urban migrants from female headed households accounted for $28 \%$ while migrants from male headed households accounted for $72 \%$ of respondents, (see Table 3). This is related with the study done by Devereux et al. (2003), which shows that male headed households did have a higher probability of leading as compared to female headed households at that particular place.

Table 3. Demographic Characteristics of Migrants in the Study Areas

\begin{tabular}{|l|l|lll|}
\hline Charactestics & No of respondents & Percent & \\
\hline Sex of household & & & \\
Male & 38 & 76 & \\
Female & 12 & 24 & \\
\hline T $\quad$ o t a l & 5 & 0 & 1 & 0 \\
\hline
\end{tabular}




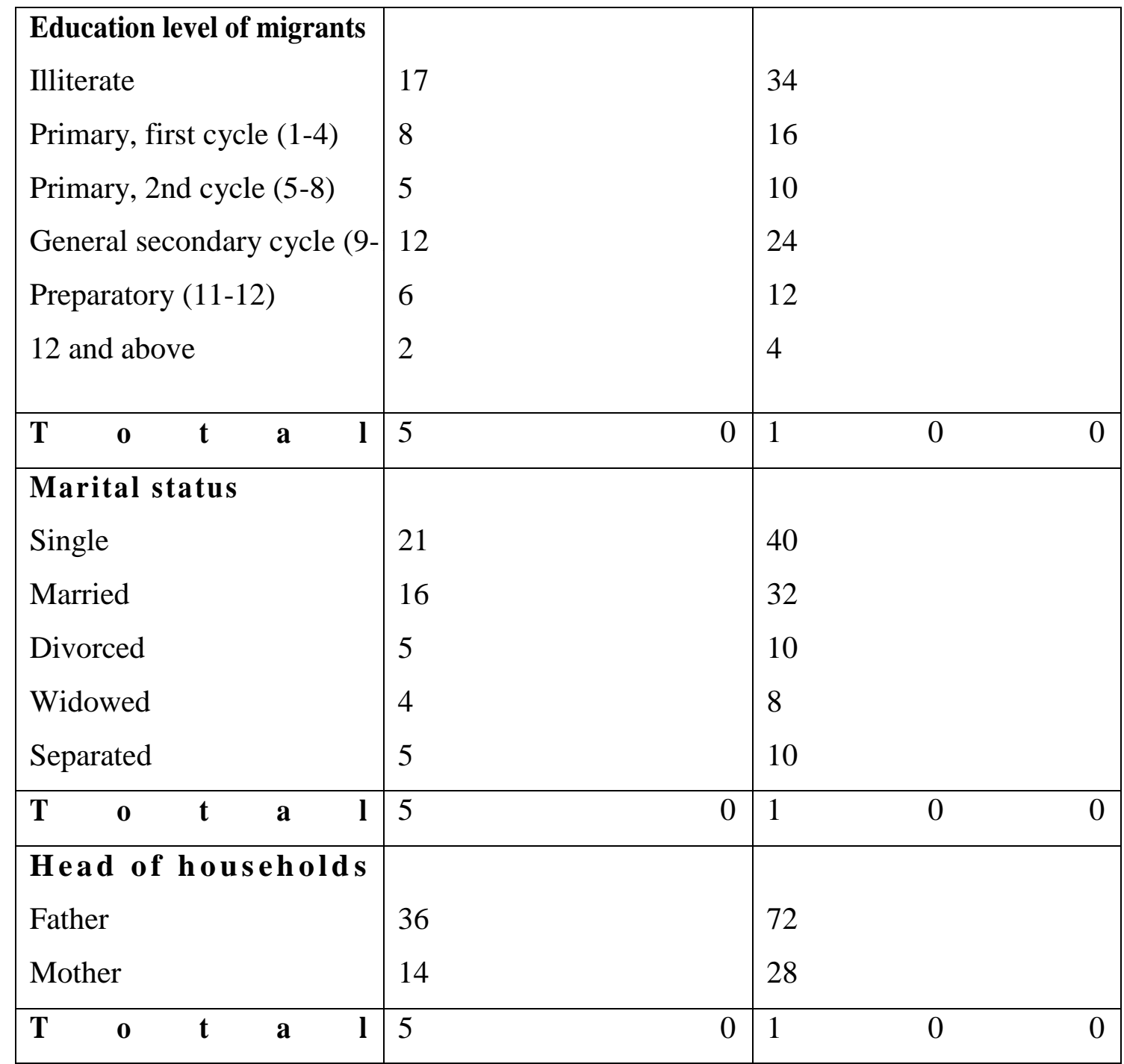

Source: Own Survey 2019

\subsection{The cause for Migration}

There are several reasons for population mobility from place. Reasons for migration to urban centers in particular are more complex. However, the causes of migration are usually identified as two broad categories, namely pushing and pulling factors. For example, people of a certain area may be pushed off by poverty and other natural factor to move towards towns for employment. On the other hand, better employment opportunities or the need for better facilities in urban areas may also pull people to different urban areas.

In addition, the decision to migrate from one place to another may also be influenced by non-economic factors such as the need to join relatives, the need to be free from cultural and family restriction and obligation and so on. In general, however, as to the causes of migration scholars concluded that migration is a response by humans to a series of economic and non-economic factors (Lewis, 1982; Todaro, 1997). However, nowadays scholars agreed that rural-urban migration is largely explained by economic factors than non-economic factors ((Todaro, 1997). In Ethiopia rural-rural migration also takes place largely as a response to economic factors rather than non-economic factors (EEA, 1999/2000). 
Table 4. Causes for migration

\begin{tabular}{|l|l|l|l|}
\hline No & Reason for migration & Frequency & Percent \\
\hline 1 & Seek employment & 15 & 30 \\
\hline 2 & Famine, poverty, land shortage, poor facilities & 7 & 14 \\
\hline 3 & To be free from cultural or family obligation & 6 & 12 \\
\hline 4 & Job transfer & 2 & 4 \\
\hline 5 & $\begin{array}{l}\text { To join immediate relatives or friends or following } \\
\text { them }\end{array}$ & 3 & 6 \\
\hline 6 & To gain education and training & 3 & 6 \\
\hline 7 & To seek modern urban services and facilities & 7 & 14 \\
\hline 8 & To open up or extended personal business & 5 & 10 \\
\hline 9 & To seek good climate & 2 & 4 \\
\hline Total & $\mathbf{5 0}$ & $\mathbf{1 0 0}$ \\
\hline
\end{tabular}

Source: Own Survey 2019

As indicated in (table 4), the majority of sample in-migrants that accounted for $30 \%$ of the total surveyed migrants in-migrated obtained job or seek employment. About $14 \%$ of sample in-migrants moved to Bombe town as a result of famine, poverty and land shortage. This is due to the fact that rural areas are highly food insecure and degraded areas. So, the only opportunity is to move to other areas for economic betterment. On the other hand, $14 \%$ of the surveyed migrants were looking for modern urban services facilities while $6 \%$ of sample in-migrants came to Wolaita Sodo town to get education and training. About $4 \%$ of sample in-migrants came to Wolaita Sodo town to join their relatives and to be Free from cultural or family restrictions and obligations. In general, the rural-urban migrants migrated to Bombe on the whole in search of economic betterment from the place of origin.

\subsection{Effects of migration}

In the study area there are many factors that make people to migrate and also migration has its own consequences in the place of destination. This study was essential to identify the living and working conditions of migrants at the destination in order to determine the impacts on them. Thus, the following section describes the type of occupation the migrants engage, the amount of income they earn, any type of skills they acquired in the capital city, challenges and risks they face upon arrival and during the course of stay in Wolaita Sodo town.

\section{a. Occupational status}

The rural-urban migrants to Wolaita Sodo town from rural areas are engaged in different urban informal economic sector activities, such as street vending, daily labor, carpenter and shop work. In terms of employment status, the subjects of this study reported that (36\%) are engaged as daily laborers, $28 \%$ are engaged in carpenter, (20\%) are self and shared employers in the street vending activity and the rest $16 \%$ are engaged in shop work (Table 5) 
According to the field survey, those of migrant street vendors are currently engaged in selling items on the streets which mostly include selling of new and second hand clothes, shoes, household utensils, electronics, cosmetics and etc. Some of the migrants are vegetable vendors and females as side walk food Sellers and others working in the construction sector. Some others engage in, additionally, as guards of construction sector and individual households and work on shop.

Table 5. Skills Acquired by Migrants

\begin{tabular}{|c|c|c|c|c|}
\hline Occupation of the House Holds & \multicolumn{2}{|c|}{ Kebeles of Migrants } & Total & Percent \\
\hline Street vendor & 5 & 5 & 10 & 20 \\
\hline Daily laborer & 10 & 8 & 18 & 36 \\
\hline Carpenter shop & 8 & 6 & 14 & 28 \\
\hline Other work & 3 & 5 & 8 & 16 \\
\hline Total & $\mathbf{2 6}$ & $\mathbf{2 4}$ & $\mathbf{5 0}$ & $\mathbf{1 0 0}$ \\
\hline
\end{tabular}

Source: Own Survey 2019

\section{b. Income of migrants}

The impact of migration on migrants as well as household economy depends on the amount of income that the migrants earned at the designation and any change in the quality of life. Table 4 shows that the majorities (48\%) of migrants earn monthly income less than 200 birr per month, $30 \%$ earn monthly income between is $200-400,12 \%$ of migrants earn monthly income of 400-600 and the rest of $8 \%$ get income above 600. In line with these, most of the migrants who live in Wolaita Sodo town are get low income. The respondents income that they have has not stay behind from consumption so the saving level of their income was too weak.

Table 6. Percentage Distribution of Income of Migrant per Month

\begin{tabular}{|l|l|l|l|}
\hline No & Income per month & Frequency & Percent \\
\hline 1 & $<200$ & 24 & 48 \\
\hline 2 & $200-400$ & 6 & 12 \\
\hline 3 & $400-600$ & 16 & 32 \\
\hline 4 & $>600$ & 4 & 8 \\
\hline Total & $\mathbf{5 0}$ & $\mathbf{1 0 0 \%}$ \\
\hline
\end{tabular}

Source: Own Survey 2019

\section{c. Skills Acquired by Migrants}

The respondents were also asked if there is skill acquired due to rural-urban migration to the capital city. These skill acquiring opportunities are not available in the rural areas and some of the skills that the migrants acquired in the capital are supposed to be changing their quality of life in the future. Accordingly, (Table 6) reveals that out of migrant respondents, $22 \%$ acquired skills related to language, and to language, and some others acquired skills 
related to masonry and carpentry (16 and 18\%), respectively. Most of the migrants (24\%) acquired the skills in other activities as urban agriculture growing, coble stone working, metal working and working related with plastic production factories car driving (one case), females food preparation etc.

Table 7. Skills Acquired by Migrants

\begin{tabular}{|l|l|l|l|}
\hline No & \multicolumn{1}{|c|}{ Skills acquired } & Frequency & Percent \\
\hline 1 & Language & 11 & 22 \\
\hline 2 & Carpenter & 9 & 18 \\
\hline 3 & Masonry & 8 & 16 \\
\hline 4 & How to run business & 12 & 24 \\
\hline 5 & Others & 10 & 20 \\
\hline \multicolumn{2}{|l|}{ Total } & $\mathbf{5 0}$ & $\mathbf{1 0 0}$ \\
\hline
\end{tabular}

Source: Own Survey 2019

\section{d. Challenges encountered by migrants}

Migrants enter into in the urban centers is part and parcel of their first exposure to the urban life and, independence from parental control. It is expected that they were facing new situations at the initial stage of adjustment and adaptation to the urban way of life in the capital city. Hence, it is also equally important as other impacts of migration to analyze what problems migrants face just at arrival and during the course of their life at place of destination.

According to (table 7), starts with the presentation of the first set of problems related to initial adjustment outlined as financial problems. Accordingly, 24\% were reported to have encountered serious financial problems, $30 \%$ of migrants reported to have faced unemployment problem just at the beginning of their stay at the place of destination. Inability to get social services (housing/accommodation, toilet, water, medication) and lack of consumable items is also expressed by migrants. Accordingly, $14 \%$ and $8 \%$ of them were faced with lack of social seservices and inability to obtain consumed iems at the time of their arrival respectively. Whether a migrant faced cultural difference (cultural shocks) or not at the time of first arrival is also examined in (Table 6). It is seen that $12 \%$ of the migrants reported to have encountered these problems and $4 \%$ of migrants reported they encountered with problem of health of one kind or the other at the time of first arrival at the current destination. On the first set adjustment other problems are also mentioned, many of the migrants expressed problems of uncertainty regarding how to behave, speak and dress like the urbanites and other problems encountered were abuses by people of destination. These include demand of higher payments during travel, greater exposure to robbery, intimidation, and etc.

This study indicates that migrants usually face problems during the course of their life in addition to the problems encountered at time of arrival. In this study, information was collected from all the migrants about the nature of the problems they faced during their stay at the place of destination. (Table 6) listed eight major problems that are encountered by 
migrants in the urban areas during their course of stay. The majority 28\%) of migrants reported that they encountered with expectation crisis i.e., they don't get job as expected, $14 \%$ of migrants reported to be vulnerable to crimes of some kind during the course of their stay at the place of destination, Social crisis/mistreatment by those of urban residents is reported by $8 \%$ of respondents, $(16 \%)$ have faced the risk of being unemployed and inability to obtain income regularly during an extended period of time, $14 \%$ have reported to feel that they have experienced unequal opportunities in every aspect of life and $6 \%$ lose ties with their rural families.

For this case migrants mentioned that they often move in groups for their safety. During data collection the researcher has also observed that they indeed move in groups. While those street vendors are selling on the street the researcher got them they cover the same place and those of daily laborers are also wondering with groups. This could be the coping strategy in protecting themselves from robbery and helping each other during the time of any accident. Lack of social service mainly homelessness among migrants was reported to be one of the most serious reported problems. This shows that the migrants are misinformed about the place of destination before they decided and came to the destination.

Table 9. Problem Encountered During the Course of Stay

\begin{tabular}{|c|l|c|c|}
\hline No & \multicolumn{1}{|c|}{ Problem Encountered during stay } & Frequency & Percent \\
\hline 1 & Susceptibility to disease & 3 & 6 \\
\hline 2 & Vulnerability to crime & 8 & 16 \\
\hline 3 & Mistreatment & 8 & 8 \\
\hline 4 & Unemployment & 7 & 16 \\
\hline 5 & Lack of social service & 3 & 6 \\
\hline 6 & Unequal opportunity in every aspects of life & 3 & 6 \\
\hline 6 & Loss of family ties & 14 & 28 \\
\hline 7 & Do not get job as expected & $\mathbf{5 0}$ & $\mathbf{1 0 0}$ \\
\hline \multicolumn{2}{|c|}{ Total }
\end{tabular}

Source: Own Survey 2019

\section{e. The decision of respondents for out-migration}

Individuals may take rational decision to leave their places with the hope of better life chances of their destinations. This is always a decision under risk and uncertainty taken under certain perception based on the information and knowledge. As seen in (Table 7) migration of the majority of the respondents $(70 \%)$ was decided by their migration was decided by their relatives after discussion with the whole family members, the remaining $10 \%$ and $7.5 \%$ of the migrants decided to move to Wolaita sodo.

Table 10. Decision for out migration 


\begin{tabular}{|l|l|l|l|}
\hline No & Decision for out migration & Frequency & Percent \\
\hline 1 & Self & 31 & 62 \\
\hline 2 & Relatives & 7 & 14 \\
\hline 3 & Family or parents & 5 & 10 \\
\hline 4 & Friends & 7 & 14 \\
\hline \multicolumn{2}{|l|}{ Total } & $\mathbf{5 0}$ & $\mathbf{1 0 0}$ \\
\hline
\end{tabular}

Source: Own Survey 2019

\section{f. Job satisfaction}

The respondents were also asked how much they are satisfied with their current work. They responded as very satisfied (18\%), somewhat satisfied (44\%), neither satisfied nor dissatisfied $(16 \%)$ and others report somewhat dissatisfied and very dissatisfied about $14 \%$ and $8 \%$ respectively (Table 11 ).

Table 11. Level of Satisfaction of Migrants in the Current Job

\begin{tabular}{|l|l|c|c|}
\hline No & Level of satisfaction & Frequency & Percent \\
\hline 1 & Very satisfied & 9 & 18 \\
\hline 2 & Somewhat satisfied & 22 & 44 \\
\hline 3 & Neither satisfied nor dissatisfied & 8 & 16 \\
\hline 4 & Somewhat dissatisfied & 7 & 14 \\
\hline 5 & Very dissatisfied & 4 & 8 \\
\hline \multicolumn{2}{|l|}{ Total } & $\mathbf{5 0}$ & $\mathbf{1 0 0}$ \\
\hline
\end{tabular}

Source: Own Survey 2019

The question why the migrants are dissatisfied with their work was raised. Accordingly, they reported that they are not using their skills, work experiences, it is not their preferred occupation, return is too low and deprived social security and they are dissatisfied due to other reasons like they do not get job as expected.

\subsection{Wolaita Sodo Town Population Conception on Rural-Urban Migration}

Rural-urban migration by the rural people is seen differently by different people or it may differ from place according to their culture. In this study, the researcher raised the question how the people on the place of origin view rural-urban migration to Wolaita Sodo Town. The reflection is that migration to study area is seen negatively by most of the rural people of the origin.

The non-migrant participants of FGD discussants told that out migration of labor is the norm and it is undertaken mostly by the poor households seasonally, during agricultural slack period as a means of securing income. They have a negative outlook towards migrants of urban areas, outlined that villagers do not have a tradition of migration to Wolaita Sodo town 
for long term except the government employees and some traders. According to the participant non-migrants in the FGD, most of the people do perceive out-migration towards urban areas exposes to disease. Thus, migration for work to Wolaita Sodo town is shame for them, mostly for females and even seasonal migration to other rural areas is not fully accepted by many people.

Participants also explained that individuals who migrate to Wolaita Sodo town either permanently or seasonally except government employees have given lower prestige not only for him/her self but to his/her families as migrants are viewed rude, thieves and losers of their culture. Thus, migration is predominantly perceived negatively by the majority of the people and taken as the last option. According to the data, although the poor and non poor members of the household are undertaking out migration to Wolaita Sodo town still there is a negative outlook towards migration and many of participants on FGD stated that the community and they themselves don't support out migration of people to Wolaita Sodo town.

\subsection{Impacts of Migration on the Place of Destination}

The impact of rural-urban migration on the host environment (urban area) has also positive and negative aspects. Rural-urban migration have contributed to the development of the town and overcoming labor shortage of the urban areas. According to Devereux et al, (2003), rural-urban migrants are considerably playing an important role in supplying cheap labor to the town, and the largest percentage of the manual labor demand of the town has been supplied by migrants.

According to the migrants of this study, it is the rural-urban labor migrants who have been contributing the largest share of labor demand in to the construction, loading and unloading, domestic work etc.in the capital city. Thus, these people are playing greater role in the development of the city. On the other hand, the negative aspect of rural-urban migration on the host environment includes exerting pressure on urban resources. Like over-crowding on social services such as; housing, transportation, and health sector, increasing urban unemployment, delinquency and, polluting the environment and etc.

\section{Conclusion}

There are towns in Ethiopia where the population growth has been very fast during recent years not only because of natural increase but as a result of migration processes. Among them, Wolaita Sodo town is one example which has experienced an accelerated growth rate of population as a result of in-migration. This research deals with the theoretical background of migration, review of literature, the nature of migrants, migration processes, the differential incidence of the rural push and urban pull factors and the consequences of migration on various aspects of socio-economic lives of the people in the areas of destination. Most migrants moved basically for economic reasons such as seeking employment, job transfer, to open up or extend personal business, to gain education and training services. On the other hand, some of them were moved to Wolaita Sodo town for non-economic reasons such as to be free from cultural or family restriction and obligation, and to join relatives or friends in the town.

Rural push factors, by and large, are stronger than the urban pull factors causing excessive to urban areas. At the same time, rural areas because of lack of agricultural or alternative employment, droughts and famines which were amongst reasons for migration. 
The urban pull factors are weak and the urban capacity is low, practically, the rural migrants perceived life chances in the destination town are highly misconstrued and rather exaggerated, based on here-say and wrong information about the opportunities available in the town.

There are several factors that induced flow of people to Wolaita Sodo town. The main determinants are low per capita income, unemployment problem and lack of goods and services in the rural area. The availability of better employment opportunities and career advancements are concentrated in the urban areas. Therefore, the relevant measures that can be taken on these determinants are expected to increase the rate of migration and did not arrest the people in their rural areas in particular. On the positive side, rural-urban migration is important in alleviating the problem of landlessness and land shortage for those who have large family size and poor economic conditions of the families. The remittances are a crucial source of income for families of poor migrants. In general, the high flow of migrants to Wolaita Sodo town has accentuated the problem of unemployment. Thus, the overall effects of rural-urban migration in the town are discouraging and hence the following recommendations are suggested to solve some of the socio-economic problems both the problems of both the places of origin and destination.

\section{References}

Adepoju, A. (1991). Introduction to population studies, Demographic lecture manual, series demographic lecture manual, series No.2. Network..

Adepoju, A. (1995). Emigration Dynamics in sub-Saharan Africa. International migration. Special Issue: Emigration Dynamics in Developing countries, vol.33, no, 314.

Adwale, A. O. (2005). Socio-Economic Factors Associated with. Urban - Rural migration in Nigeria: A Case study of Oyo State. Jornal of Human Ecology

Aliyev, I. (2008). Rural-Urban Migration in Azerbaijan. MA.] Thesis in Public policy, Europea University.

Andersen, L. E. (2002). Rural - Urban Migration in Bolvia: Advantages and Disadvantages. Institute for Socio-Economic Research. Universidad CatholicaBolviana La Paz, Bolvia.

Befekadu Degefe. (1978). Migration and Urbanization in Ethiopia: A Discussion Paper presented for the Seminar on Population and Employment planning, Addis Ababa University.

Berhanu, B.and M.J. White. (2000). War, Famine and Female Migration in Ethiopia. 19601989: Economic Development and cultural change, 49(1):91-113.

Birru Busha. (1997). Causes and consequences of rural -urban Labor Migration in Ethiopia: The case of Bombe town MA .Thesis in Geography, Addis Ababa University.

Bejewel, G. (1989). Migration to Shashemene: Ethnicity, Gender and. Occupation in Urban Ethiopia.PHD Dissertation, Uppsala, Scandinavian Institute of African Studies.

CSA. (1999). Statistical Report on the 1999 National Labor Force Survey, Addis Ababa, Ethiopia.

De Haan, A. (2000). Migrants, Livelihoods, and Rights: The Relevance of Migration in Development Policies. Social development working paper No.4.

Degefa Tolossa. (2005). Rural Livelihoods, Poverty and Food Insecurity in Ethiopia: A case study at Ernessa and Garb Garbi Communities in Oromya Zone, Amharic National 
Deshingkar, P., and. Grimm, S. (2005). Voluntary Internal Migration. A Global Perspective.IOM Migration Research Series No. 19.

Ezra. (2001). Ecological Degradation, Rural poverty, and Migration in Ethiopia working paper, No. 149.

Ezra. G.E. (2001). Rural Out-Migration in the Drought -Prone Areas of Ethiopia.

Farooq M and Cheeme, M.A. (2005). Likelihood Impact of Internal Migration on Family Institution in Punjab, Pakistan: Journal of Agriculture and Social Science. 